\title{
RETRACTION
}

\section{Bleomycin/interleukin-12 electrochemogene therapy for treating naturally occurring spontaneous neoplasms in dogs}

\section{SD Reed, A Fulmer, J Buckholz, B Zhang, J Cutrera, K Shiomitsu and S Li}

Cancer Gene Therapy (2010) 17, 826; doi:10.1038/cgt.2010.59

Correction to: Cancer Gene Therapy (2010) 17, 571-578; doi:10.1038/cgt.2010.13

An editorial error led to duplicate publication in Cancer Gene Therapy of 'Bleomycin/interleukin-12 electrochemogene therapy for treating naturally occurring spontaneous neoplasms in dogs,' by Reed et al.: once in CGT 17.7 (doi:10.1038/cgt.2010.6) and again in CGT 17.8 (doi:10.1038/ cgt.2010.13). The article with DOI 10.1038/cgt.2010.13 has been retracted, leaving 2010.6 as the version of record. 